\title{
Sweat glands of the scrotum of the bull
}

\author{
N. B. Blazquez*, G. J. Mallard and S. R. Wedd \\ Department of Animal Husbandry, University of Bristol, School of Veterinary Science, \\ Langford House, Langford, Bristol BS18 7DU, U.K.
}

\begin{abstract}
Summary. Skin samples were taken post mortem from the scrotum, abdomen and neck of 4 mature bulls. The volume of sweat glands per unit skin surface area of the scrotum was greater than that of other body regions. Within the scrotum there was a gradient in sweat gland volume increasing from proximal through to distal parts of the scrotum. These results suggest a previously unidentified variable cooling capacity of the scrotum depending on testicular descent.
\end{abstract}

Keywords: scrotum; sweat glands; thermoregulation; spermatogenesis; bull; morphometry

\section{Introduction}

In sexually mature males of many mammalian species, including bovids, spermatogenesis proceeds at a temperature below core temperature (Waites, 1970). Elevated testicular temperature causes disruption of the seminiferous tubules and results in semen of decreased quality (Moore \& Oslund, 1924; Moule \& Waites, 1963). The difference between testicular and core temperature is maintained by a number of effectors (see Waites, 1970) and these include: the pampiniform plexus, where heat is lost from the incoming testicular arteries to the veins by a counter-current heat-exchange system; the dartos and cremaster muscles, which can variably reduce the surface area of the scrotum and draw the testes closer to the abdomen; variations in scrotal skin blood flow; and the scrotal sweat glands.

That the scrotal sweat glands have an important role in testicular thermoregulation in the bull was indicated by the observation that, in a hot environment, cutaneous moisture evaporation per unit skin surface area from the scrotum was greater than that from the general body surface (Robertshaw \& Vercoe, 1980), and by reports that scrotal sweat glands were much larger than those elsewhere on the body (Weiner \& Hellman, 1960; Waites \& Voglmayr, 1962; Lyne \& Hollis, 1968; Amakiri, 1974). These morphological studies were not, however, substantiated by detailed quantitative measurements. The present article describes a detailed morphometric examination of the scrotal sweat glands of bulls.

\section{Materials and Methods}

Skin samples from the neck, ventral abdomen, and proximal, middle and distal scrotum (Fig. 1) were taken post mortem from 4 bulls. Three were Friesians and 1 was of an unknown breed. The bulls were about $12-15$ months of age. All were sexually mature as indicated by spermatozoa in the tail of the epididymis, and by normal spermatogenesis in histological sections of the testes.

Sweat gland volume and sweat gland surface area per unit skin surface area (SSA) were calculated from fixed frozen histological sections as described previously (Blazquez et al., 1987b). Briefly, this involved measuring the sweat gland profile areas and perimeters on frozen sections taken perpendicular to the skin surface. These measurements were then divided by the overlying skin surface length and multipled by one unit depth to give an estimate of sweat gland volume per unit SSA $\left(\mu \mathrm{m}^{3} / \mu \mathrm{m}^{2}\right)$ and sweat gland surface area per unit SSA $\left(\mu \mathrm{m}^{2} / \mu \mathrm{m}^{2}\right)$. Dimensions of

*Present address: Department of Anatomy, University of Bristol, Medical School, Bristol BS8 1TD, U.K. 


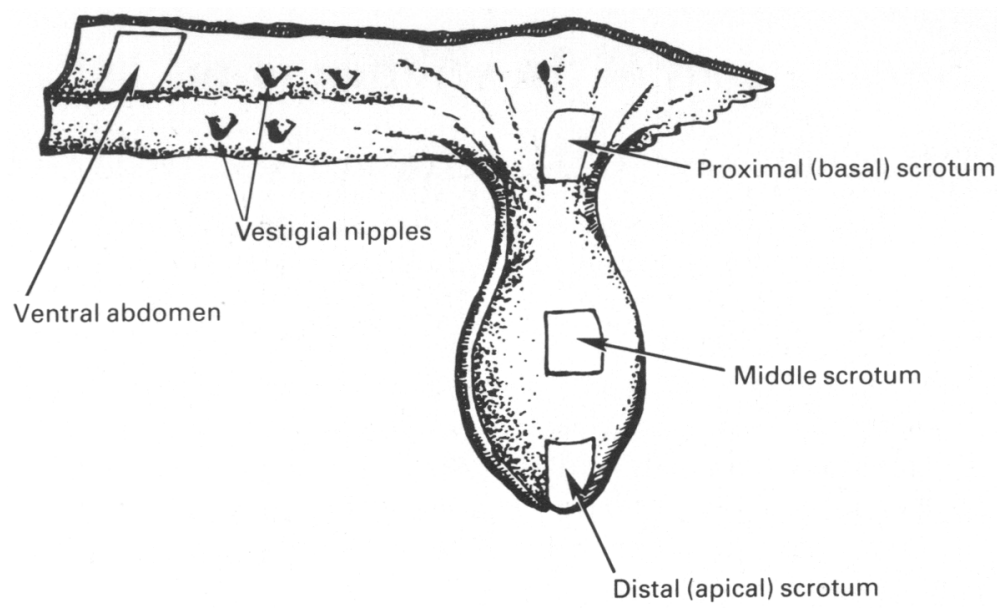

Fig. 1. Diagram illustrating sample sites on the scrotum and contiguous ventral abdominal skin.

individual sweat glands were estimated by dividing the sweat gland volume or area per unit SSA by the number of hair follicles per unit SSA. This is acceptable since in bulls there is a one-to-one relationship between sweat glands and hair follicles (Carter \& Dowling, 1954).

Data were corrected for fixation-induced shrinkage (see below), subjected to a $\log _{10}$ transformation and analysed by a blocked analysis of variance. Differences between means were compared by a $t$ test when there were significant $F$ ratios. Tissue shrinkage was estimated by measuring the samples before and after fixation. The mean shrinkage was $13 \%$. There was no statistical difference in shrinkage between sites.

\section{Results}

At all sites sweat glands were associated with hair follicles and were never seen to open directly onto the skin surface. Sections of scrotal skin showed a greater number of rounded sweat gland profiles than did sections of neck skin. This suggested that, although tubular in both sites, sweat glands were more coiled in the scrotum (Figs 2 and 3). Abdominal sweat glands were similar to those of the scrotum save that they extended only about $1 \mathrm{~mm}$ from the epidermis compared to $3 \mathrm{~mm}$ in parts of the scrotum.

Sweat gland volume and area per unit SSA in the distal scrotum were greater than in any of the other body regions. There was an increase in scrotal sweat gland dimensions per unit SSA from proximal, through mid- to distal scrotum. Neck and all scrotal sweat gland volumes were greater than those of the abdomen (Table 1).

The number of hair follicles and therefore sweat glands per unit SSA varied between body regions (Table 1). Taking this into account, the mean volume of an individual sweat gland of the distal scrotum was calculated to be between 4 and 5 times that of the neck. Whilst there was still a gradient in individual sweat gland volumes moving distally towards the apex of the scrotum, there was no difference between neck or abdominal sweat gland volumes (Table 1).

\section{Discussion}

The estimates of the volume and density of neck sweat glands obtained in the present study are similar to those reported by other workers (Taneja, 1960; Findlay \& Jenkinson, 1964; Jenkinson \& Nay, 1972; Robertshaw \& Vercoe, 1980; Blazquez et al., 1987a). It is more difficult to compare values for the scrotum, however, because previous workers (Wiener \& Hellman, 1960; Mykytowycz \& Nay, 1964; Lyne \& Hollis, 1968; Amakiri, 1974) have not stated the location on the scrotum 

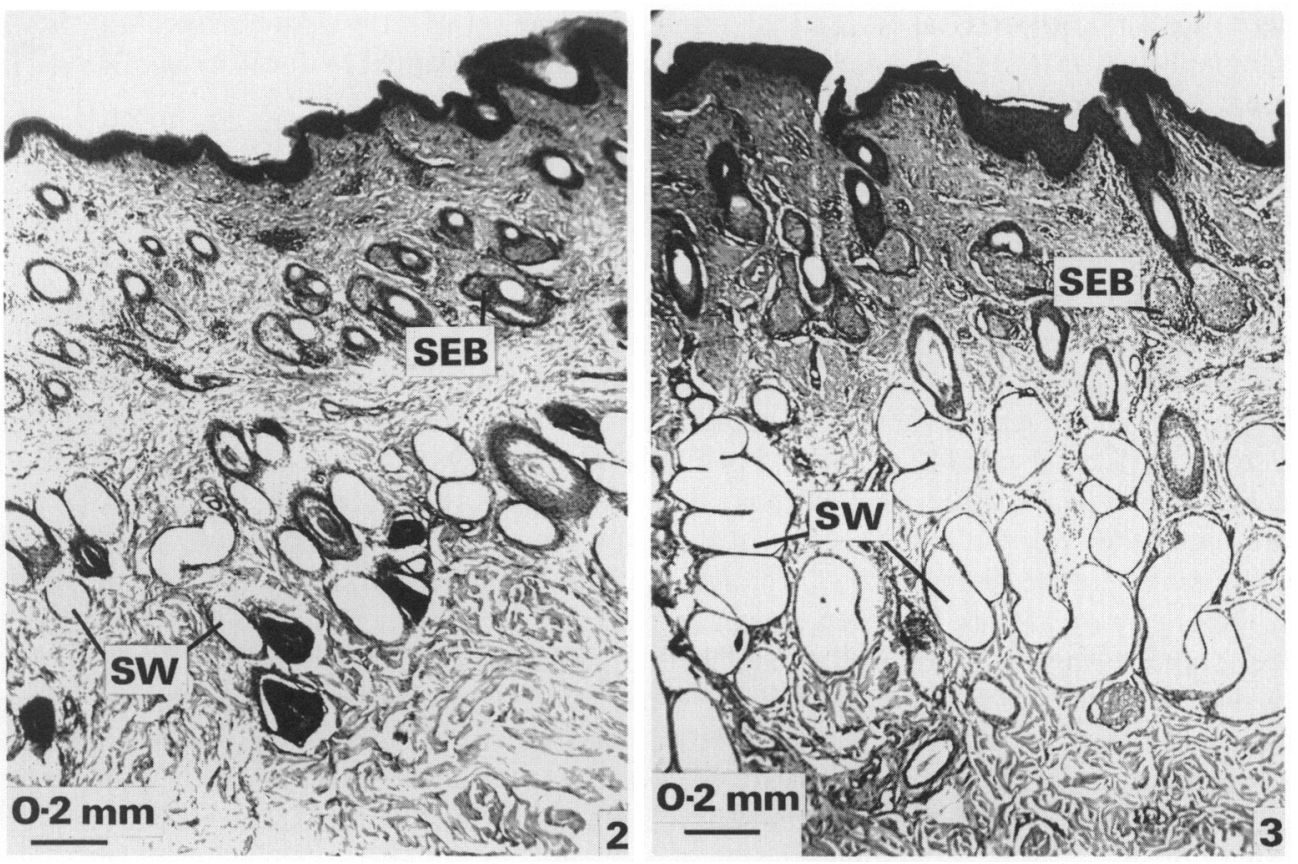

Fig. 2. Frozen section of neck skin showing sweat (SW) and sebaceous (SEB) glands.

Fig. 3. Frozen section of skin from the distal scrotum showing sweat (SW) and sebaceous (SEB) glands.

Table 1. Mean \pm s.e.m. sweat gland dimensions and number of hair follicles per unit skin surface area, and individual sweat gland volumes and area in different body regions of 4 mature bulls (values in parentheses are the $\log _{10}$ transformed data to which the least significant differences (LSD) relate)

\begin{tabular}{|c|c|c|c|c|c|}
\hline Sample site & $\begin{array}{c}\text { Sweat gland } \\
\text { volume } \\
\left(\mu \mathrm{m}^{3} / \mu \mathrm{m}^{2} \text { skin }\right)\end{array}$ & $\begin{array}{c}\text { Sweat gland } \\
\text { area } \\
\left(\mu \mathrm{m}^{2} / \mu \mathrm{m}^{2} \text { skin }\right)\end{array}$ & $\begin{array}{l}\text { No. of hair } \\
\text { follicles } / \mathrm{cm}^{2}\end{array}$ & $\begin{array}{l}\text { Sweat gland } \\
\text { volume } \\
\left(\mu \mathrm{m}^{3} \times 10^{6}\right)\end{array}$ & $\begin{array}{l}\text { Sweat gland } \\
\text { area } \\
\left(\mu \mathrm{m}^{2} \times 10^{4}\right)\end{array}$ \\
\hline Neck & $\begin{array}{c}138.9 \pm 13.48 \\
(2 \cdot 13)\end{array}$ & $\begin{array}{c}3 \cdot 1 \pm 0.27 \\
(0 \cdot 48)\end{array}$ & $\begin{array}{c}1612 \pm 182 \cdot 4 \\
(3 \cdot 18)\end{array}$ & $\begin{array}{c}9.0 \pm 0.86 \\
(6.94)\end{array}$ & $\begin{array}{c}20 \cdot 0 \pm 1 \cdot 51 \\
(1.29)\end{array}$ \\
\hline $\begin{array}{l}\text { Ventral } \\
\text { abdomen }\end{array}$ & $\begin{array}{c}50 \cdot 5 \pm 3.95 \\
(1.69)\end{array}$ & $\begin{array}{c}1 \cdot 6 \pm 0.08 \\
(0 \cdot 20)\end{array}$ & $\begin{array}{c}749 \pm 157 \cdot 5 \\
(2 \cdot 78)\end{array}$ & $\begin{array}{c}11 \cdot 5 \pm 3 \cdot 81 \\
(6 \cdot 91)\end{array}$ & $\begin{array}{c}34.5 \pm 10.53 \\
(1.42)\end{array}$ \\
\hline \multicolumn{6}{|l|}{ Scrotum } \\
\hline Proximal & $\begin{array}{c}82 \cdot 1 \pm 13.26 \\
(1 \cdot 88)\end{array}$ & $\begin{array}{c}2 \cdot 1 \pm 0 \cdot 24 \\
(0 \cdot 31)\end{array}$ & $\begin{array}{c}532 \pm 51 \cdot 7 \\
(2 \cdot 71)\end{array}$ & $\begin{array}{c}17 \cdot 2 \pm 3 \cdot 17 \\
(7 \cdot 14)\end{array}$ & $\begin{array}{c}40 \cdot 7 \pm 6 \cdot 27 \\
(1.58)\end{array}$ \\
\hline Middle & $\begin{array}{c}143.6 \pm 10 \cdot 05 \\
(2 \cdot 15)\end{array}$ & $\begin{array}{c}3.0 \pm 0 \cdot 17 \\
(0.48)\end{array}$ & $\begin{array}{c}720 \pm 42 \cdot 8 \\
(2 \cdot 85)\end{array}$ & $\begin{array}{c}20 \cdot 7 \pm 2 \cdot 44 \\
(7 \cdot 30)\end{array}$ & $\begin{array}{c}44.0 \pm 5.06 \\
(1.62)\end{array}$ \\
\hline Distal & $\begin{array}{c}256 \cdot 4 \pm 39 \cdot 06 \\
(2 \cdot 37)\end{array}$ & $\begin{array}{c}4 \cdot 7 \pm 0 \cdot 70 \\
(0 \cdot 64)\end{array}$ & $\begin{array}{c}744 \pm 107.9 \\
(2.83)\end{array}$ & $\begin{array}{c}40 \cdot 1 \pm 7 \cdot 71 \\
(7 \cdot 54)\end{array}$ & $\begin{array}{c}75.3 \pm 15.19 \\
(1.81)\end{array}$ \\
\hline LSD $P<0.05$ & $0 \cdot 16$ & $0 \cdot 12$ & $0 \cdot 19$ & $0 \cdot 26$ & $0 \cdot 23$ \\
\hline$P<0.01$ & $0 \cdot 21$ & $0 \cdot 16$ & 0.26 & $0 \cdot 35$ & $0 \cdot 31$ \\
\hline$P<0.001$ & $0 \cdot 28$ & 0.21 & 0.35 & 0.46 & 0.41 \\
\hline
\end{tabular}


where their samples were taken. As they quote only one set of values for the scrotum they were presumably unaware of the dramatic difference in size from proximal to distal areas observed in the present study.

When bulls were placed in an environment of $40^{\circ} \mathrm{C}$, the moisture loss (in terms of $\mathrm{g} \cdot \mathrm{m}^{-2} \cdot \mathrm{h}^{-1}$ ) from the whole scrotum was greater than that of the general body surface (Robertshaw \& Vercoe, 1980), and it was concluded that larger sweat glands discharged more sweat than did smaller sweat glands. In the light of the present study and on the basis of the results of Robertshaw \& Vercoe (1980), it would appear that the potential for sweat production is not uniform throughout the scrotum but increases towards the apex of the scrotum.

Scrotal skin surface temperatures show a gradient similar to that of the scrotal sweat glands, with the apex of the scrotum some $2^{\circ} \mathrm{C}$ cooler than the middle and some $4^{\circ} \mathrm{C}$ cooler than the base of the scrotum (Riemerschmid \& Quilan, 1941; Purohit et al., 1985). These gradients, in sweat gland size and scrotal temperature, may reflect an ability of the scrotum to cool specific parts of the testes more than others. In the bull, the part of the testis nearest to the largest glands is the tail of the epididymis where the spermatozoa are stored. An increase in the storage temperature of spermatozoa, before insemination, has been shown to result in increased embryonic death (Burfening \& Ulberg, 1968), suggesting that adequate thermoregulation of the epididymal tail is important. However, whether this region requires to be cooled more than the seminiferous tubules is open to debate since elevated testicular temperature has been shown to damage the seminiferous tubules (Moore \& Oslund, 1924).

An alternative hypothesis is that the scrotal sweat gland gradient constitutes a variable cooling capacity of the scrotum depending on testicular descent. In hot environments when the testes are fully descended they would be next to the largest sweat glands. Direct heat loss from the testes would be increased due to the increased evaporative cooling effects of sweating. There would also be increased heat loss from the testicular veins as they course over the surface of the descended testis. This would permit greater cooling of the incoming arterial blood as a result of increased heat exchange at the pampiniform plexus.

The fine control over testicular temperature may therefore not only involve the degree of tunica dartos contraction and the amount of sweat gland discharge, but may also be influenced by the variable sweat gland density in the scrotum.

\section{References}

Amakiri, A.D. (1974) Sweat gland measurements in some tropical and temperate breeds of cattle in Nigeria. Anim. Prod. 18, 285-29I.

Blazquez, N.B., Batten, E.H., Long, S.E. \& Perry, G.C. (1987a) A quantitative morphological examination of bovine vulval skin glands. J. Anat. 155, 153-163.

Blazquez, N.B., Long, S.E., Perry, G.C. \& Watson, E.D. (1987b) Effect of oestradiol-17 $\beta$ on skin glands in heifer calves. $J$. Endocr. 115, 43-46.

Burfening, P.J. \& Ulberg, L.C. (1968) Embryonic survival subsequent to culture of rabbit spermatozoa at $30^{\circ} \mathrm{C}$ and $40^{\circ} \mathrm{C}$. J. Reprod. Fert. 15, 87-92.

Carter, H.B. \& Dowling, D.F. (1954) Hair follicle and apocrine population of cattle skin. Aust. J. agric. Res. 5, 745-754.

Findlay, J.D. \& Jenkinson, D.M. (1964) Sweat gland function in the Ayrshire calf. Res. vet. Sci. 5, 109-115.

Jenkinson, D.M. \& Nay, T. (1972) The sweat glands and hair follicles of European cattle. Aust. J. biol. Sci. 25, 585-595.

Lyne, A.G. \& Hollis, D.E. (1968) The skin of sheep: A comparison of body regions. Aust. J. biol. Sci. 21, 499-527.

Moore, C.R. \& Oslund, R. (1924) Experiments on the sheep testis - cryptorchidism, vasectomy and scrotal insulation. Am. J. Physiol. 67, 595-601.

Moule, G.R. \& Waites, G.M.H. (1963) Seminal degeneration in the ram and its relation to the temperature of the scrotum. J. Reprod. Fert. 5, 433-446.

Mykytowycz, R. \& Nay, T. (1964) Study of the cutaneous glands and hair follicles of some species of macropodidae. CSIRO Wildl. Res. 9, $200-217$.

Purohit, R.C., Hudson, R.S., Riddel, M.G., Carson, R.L., Wolf, D.F. \& Walker, D.F. (1985) Thermography of the bovine scrotum. Am. J. vet. Res. 46, 2388-2392.

Riemerschmid, G. \& Quilan, J. (1941) Further observations on the scrotal skin temperature of the bull, with some remarks on the intra-testicular temperature. Onderstepoort J. vet. Sci. Anim. Ind. 17, 123-140.

Robertshaw, D. \& Vercoe, J.E. (1980) Scrotal thermoregulation of the bull (Bos spp.). Aust. J. agric. Res. 31, $401-407$. 
Taneja, G.C. (1960) Density of sweat glands and its relationship with cutaneous evaporation. J. agric. Sci., Camb. 55, 109-110.

Waites, G.M.H. (1970) Temperature regulation and the testis. In The Testis, vol. 1, pp. 241-279. Eds A. D. Johnson, W. R. Gomes \& N. L. VanDemark. Academic Press, New York.
Waites, G.M.H. \& Voglmayr, J.K. (1962) Apocrine sweat glands of the scrotum of the ram. Nature, Lond. 196, 965-967.

Weiner, J.S. \& Hellman, K. (1960) The sweat glands. Biol. Rev. 35, 141-186.

Received 19 October 1987 